Supporting Information for

\title{
A hierarchical anodic aluminum oxide template
}

Youdi $\mathrm{Hu}^{1,2}$, Xiao Wang ${ }^{1}$, Meng Zhang ${ }^{1}$, Shuaiqi Wang ${ }^{1}$, Shunde $\mathrm{Li}^{1}$, and Gang Chen ${ }^{1,2, *}$

${ }^{1}$ School of Physical Science and Technology, ShanghaiTech University, Shanghai 201210, China

${ }^{2}$ University of Chinese Academy of Sciences, No. 19A Yuquan Road, Beijing 100049, China

*e-mail: gchen@shanghaitech.edu.cn 


\section{Methods}

Materials. Polystyrene microspheres (PS-MSs, weight percentage of $5 \mathrm{wt} \%, 1.5 \mu \mathrm{m}$ in diameter) were purchased from Huge Biotechnology (Shanghai, China). Polished aluminum foils (99.999\%) were purchased from Topmembranes Technology Co., Ltd (Shenzhen, China). Titanium diisopropanol bis(acetylacetonate) (TIACA) was purchased from Sigma-Aldrich. Tetraethyl orthosilicate (TEOS) was purchased from Sinopharm Chemical Reagent Co., Ltd (Shanghai, China). Tetrakis(dimethylamino)titanium (TDMAT) was purchased from KLD Vacuum Technologies Co., Ltd (Wuhan, China).

Preparation of the hAAO template. The polished aluminum foil was annealed at $500{ }^{\circ} \mathrm{C}$ for one hour to release stress. After that, the first anodization was carried out under the constant DC voltage of $40 \mathrm{~V}$ in $0.3 \mathrm{M}$ oxalic acid at $7{ }^{\circ} \mathrm{C}$ for $7 \mathrm{~h}$. The ordered aluminum nanohollow array (ANA) was obtained by removing the porous anodic alumina layer by immersing the foil into the mixed solution of $6.0 \mathrm{wt} \% \mathrm{H}_{3} \mathrm{PO}_{4}$ and $1.8 \mathrm{wt} \% \mathrm{H}_{2} \mathrm{CrO}_{4}$ at $60{ }^{\circ} \mathrm{C}$ for $8 \mathrm{~h}$. The PS-MS emulsion (5 wt $\%, 1.5 \mu \mathrm{m}$ ) was diluted with ethanol and deionized water in a volume ratio of $6: 4: 10$ (emulsion: ethanol: deionized water). The diluted PS-MS mixture was injected slowly onto the water surface in a petri dish. A close-packed monolayer of PS-MSs was formed on the water surface with structural colors. The ordered ANA substrate was then immersed into the water to transfer the PS-MS monolayer onto its surface. Subsequently, the monolayer of PS-MSs was etched by oxygen plasma at the oxygen flow rate of $2 \mathrm{sccm}$ (standard cubic centimeter per minute) with the power of $20 \mathrm{~W}$ and the frequency of $40 \mathrm{kHz}$ to reduce the PS-MS size (Femto 
Science, Plasma System CUTE). The diameter of PS-MSs was reduced to $1.45,1.3$, and $1.0 \mu \mathrm{m}$ by etching for 50,90, and 150 min, respectively. To prepare the $\mathrm{SiO}_{2}$-covered ANA substrate, a 250-nm thick $\mathrm{SiO}_{2}$ layer was sputtered onto the ANA-supported PS-MS substrate and the PS-MSs were removed using the Scotch tape. The second anodization was conducted on the $\mathrm{SiO}_{2}$-covered ANA substrate under the same conditions as the first anodization for $10 \mathrm{~min}$. The hAAO template was formed by enlarging the nanochannel diameter from $40 \mathrm{~nm}$ to $80 \mathrm{~nm}$ by immersing in the $5 \mathrm{wt} \% \mathrm{H}_{3} \mathrm{PO}_{4}$ solution for $30 \mathrm{~min}$.

Fabrication of the radial $\mathrm{TiO}_{2}$ nanopillar array. The radial $\mathrm{TiO}_{2}$ nanopillar array was fabricated by the ALD technique (ALD-T200Q, Wuhan KLD Vacuum Technologies Co. Ltd.). Tetrakis(dimethylamino)titanium (TDMAT) and distilled water were used as the precursors. The substrate temperature was set at $200{ }^{\circ} \mathrm{C}$. The TDMAT and $\mathrm{H}_{2} \mathrm{O}$ vapors were delivered to the growth chamber using the $\mathrm{N}_{2}$ carrier gas at a flow rate of $15 \mathrm{sccm}$. One $\mathrm{TiO}_{2}$ growth cycle consisted of TDMAT (0.15 s), holding (15 s), $\mathrm{N}_{2}$ (15 s), $\mathrm{H}_{2} \mathrm{O}(0.02 \mathrm{~s})$, holding (15 s), and $\mathrm{N}_{2}$ (15 s). The $\mathrm{TiO}_{2}$ growth rate was about $0.045 \mathrm{~nm}$ per cycle. Then, a poly(methyl methacrylate) (PMMA) film was spin-coated onto the surface of the hAAO template as the supporting layer. Next, the back Al was removed using the mixture of $300 \mathrm{ml}$ of the saturated $\mathrm{CuCl}_{2}$ solution and $20 \mathrm{ml}$ of the $37 \% \mathrm{HCl}$ solution. Finally, the radial $\mathrm{TiO}_{2}$ nanopillar array was fabricated by etching the alumina nanochannels in the hAAO template using the $5 \mathrm{wt} \% \mathrm{H}_{3} \mathrm{PO}_{4}$ solution.

Fabrication of the radial $\mathrm{SiO}_{2}$ nanopillar array. The radial $\mathrm{SiO}_{2}$ nanopillar array was fabricated by the TEOS decomposition. The precursor solution was prepared by adding $1 \mathrm{ml}$ of TEOS, $1 \mathrm{ml}$ of $0.1 \mathrm{M}$ diluted hydrochloric acid and $1.5 \mathrm{ml}$ of ethanol, followed by stirring at 
room temperature. The hAAO template was then immersed into the precursor solution to fill the nanochannels. Eventually, the radial $\mathrm{SiO}_{2}$ nanopillar array was fabricated by calcining at $500{ }^{\circ} \mathrm{C}$ to turn TEOS into $\mathrm{SiO}_{2}$, followed by removing the back $\mathrm{Al}$ and the alumina nanochannels.

Fabrication of the radial PMMA nanopillar array. The PMMA solution was prepared by dissolving the PMMA powder into toluene. The radial PMMA nanopillar array was acquired by drop coating the PMMA solution on the hAAO surface at $100^{\circ} \mathrm{C}$, followed by removing the back $\mathrm{Al}$ and the alumina nanochannels.

Fabrication of the radial carbon nanopillar array. The glucose solution was prepared by dissolving the glucose powder into the DI water. The hAAO template was then immersed into the precursor solution to fill the nanochannels. The radial carbon nanopillar array was obtained by calcining at $500{ }^{\circ} \mathrm{C}$ to carbonize glucose and followed by removing the back $\mathrm{Al}$ and the alumina nanochannel walls.

Fabrication of the $\mathrm{TiO}_{2}$ and $\mathrm{Ag}$ moth-eye-like nanoarrays. The D-hAAO template was fabricated by removing the alumina nanochannels in the hAAO template with the $5 \mathrm{wt}^{0} \mathrm{H}_{3} \mathrm{PO}_{4}$ solution. $\mathrm{TiO}_{2}$ was deposited into the D-hAAO template by spraying pyrolysis at $450{ }^{\circ} \mathrm{C}$. The precursor solution was $0.38 \mathrm{M}$ titanium diisopropoxide bis(acetylacetonate) (TIACA) in ethanol. The 300-nm thick Ag layer was deposited by magnetron sputtering at a rate of $0.5 \AA / \mathrm{s}$. A PMMA film was spin-coated as the supporting layer. $\mathrm{The}^{\mathrm{TiO}_{2}}$ and $\mathrm{Ag}$ moth-eye-like nanoarrays were obtained by removing the back $\mathrm{Al}$ using the mixture of $300 \mathrm{ml}$ of the saturated $\mathrm{CuCl}_{2}$ solution and $20 \mathrm{ml}$ of the $37 \mathrm{wt} \% \mathrm{HCl}$ solution. 
Characterizations. The GISAXS measurement was carried out at beamline BL16B1 of Shanghai Synchrotron Radiation Facility (SSRF). The incident photon energy was $10 \mathrm{keV}$ (wavelength $=1.2398 \AA$ ) at the incident angle of $0.3^{\circ}$ and the exposure time of $100 \mathrm{~s}$ using the 2D Mar165 CCD detector. The morphologies of the hAAO templates and nanoarrays were characterized by the Joel 7800 SEM. The extinction spectrum was obtained by an Agilent Technologies Cary Series UV-vis-NIR spectrometer. The transmission spectrum was measured using the Ideaoptics R1 angle-resolved spectrum system. XPS measurements were carried out using ThermoFisher ESCALANTM 250Xi. Raman spectra were measured using the ANDOR Raman Spectrometer. The contact angle measurement was carried out using Kino SL200KS. The electric field distribution was simulated using the COMSOL Multiphysics software. 


\section{Supporting Figures:}
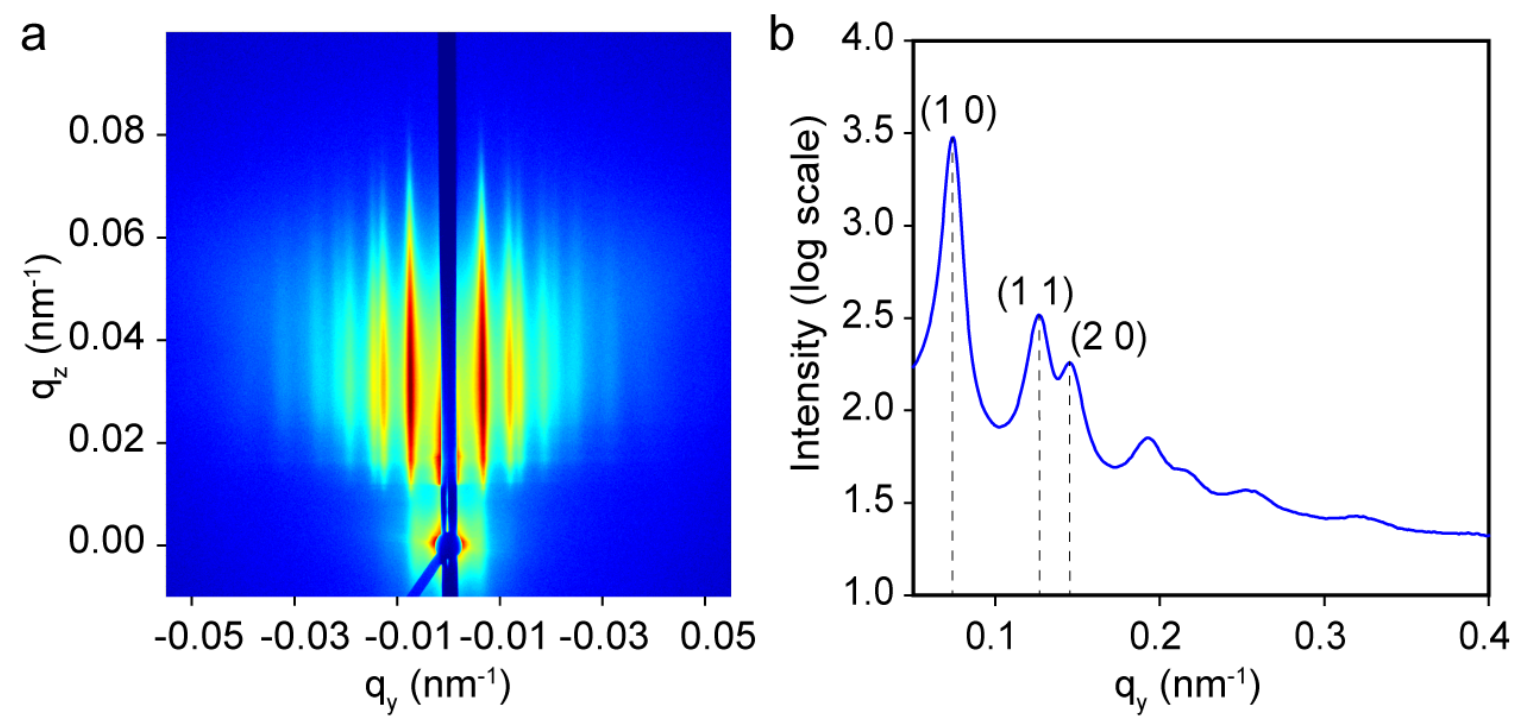

Figure S1. The GISAXS measurement of the ANA array. The diffraction rods appear in the GISAXS pattern at the scattering wavevector transfer $\mathrm{q}_{\mathrm{y}}$ of $\pm 0.074, \pm 0.126, \pm 0.145 \mathrm{~nm}^{-1}$, corresponding to the (1 0$),\left(\begin{array}{ll}1 & 1\end{array}\right),\left(\begin{array}{ll}2 & 0\end{array}\right)$ planes of a 2D hexagonal structure. 


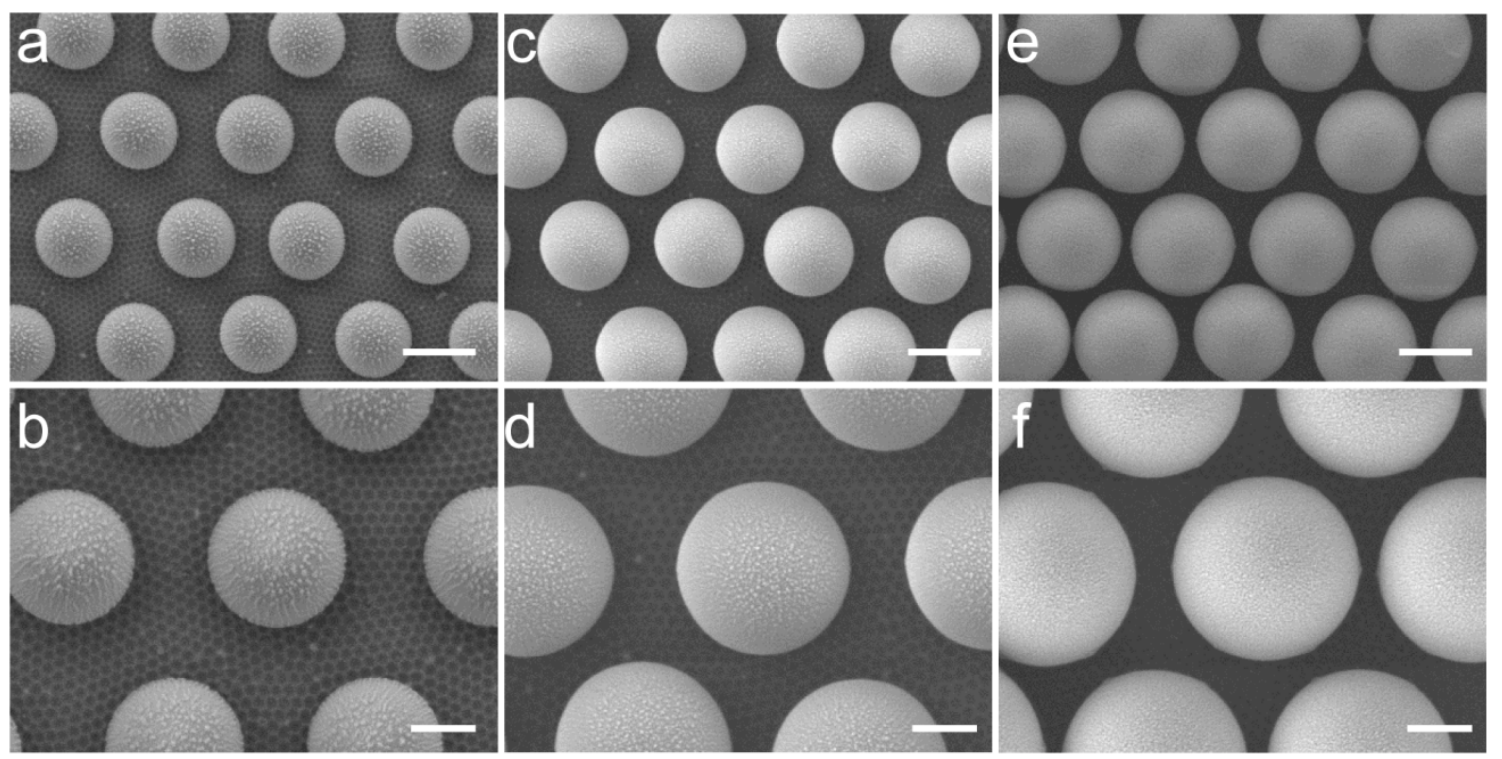

Figure S2. The PS-MSs on the ANA substrates are etched by oxygen plasma. The PS-MS diameters are: (a, b) $1.0 \mu \mathrm{m},(\mathrm{c}, \mathrm{d}) 1.3 \mu \mathrm{m}$ and (e, f) $1.45 \mu \mathrm{m}$. The scale bars in (a), (c) and (e) are $1 \mu \mathrm{m}$ and in (b), (d) and (f) are $500 \mathrm{~nm}$. 


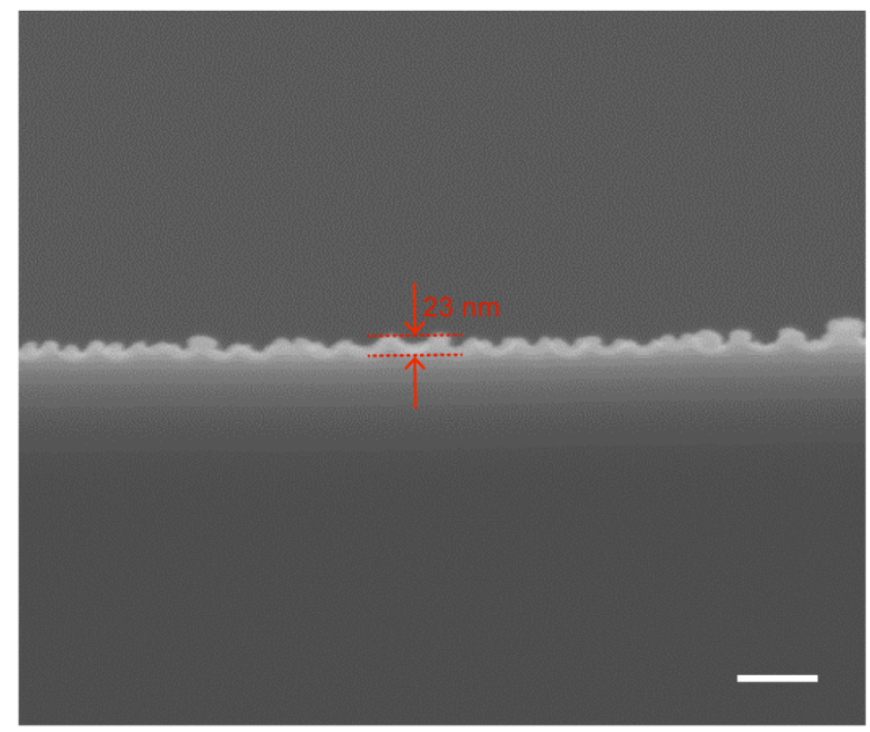

Figure S3. The cross-sectional SEM image of the ANA substrate obtained by the Ar ion milling. The scale bar is $200 \mathrm{~nm}$. There are small tips protruding on the ANA substrate with a height of 20-30 nm, which reduces the contact areas between PS-MSs and the substrate. The distance between the adjacent tips is $100 \mathrm{~nm}$. 


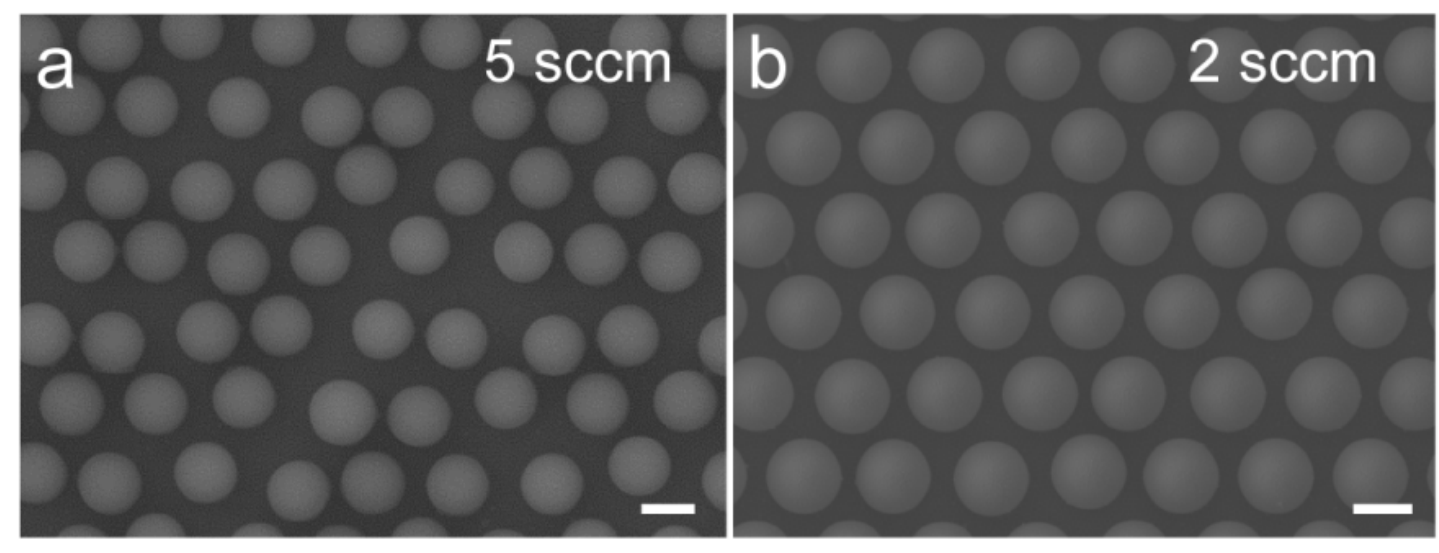

Figure S4. The SEM images of the PS-MSs on the ANA substrates. The initial diameter of PS-MSs is $1.5 \mu \mathrm{m}$. The PS-MSs are etched by $\mathrm{O}_{2}$ plasma with the $\mathrm{O}_{2}$ flow of (a) $5 \mathrm{sccm}$ and (b) $2 \mathrm{sccm}$ for $90 \mathrm{~min}$. The scale bars are $1 \mu \mathrm{m}$. Due to surface charges induced by oxygen plasma, it is crucial to operate under low power, low frequency and small oxygen flow rate to maintain the initial ordered structure of the PS-MS array. 

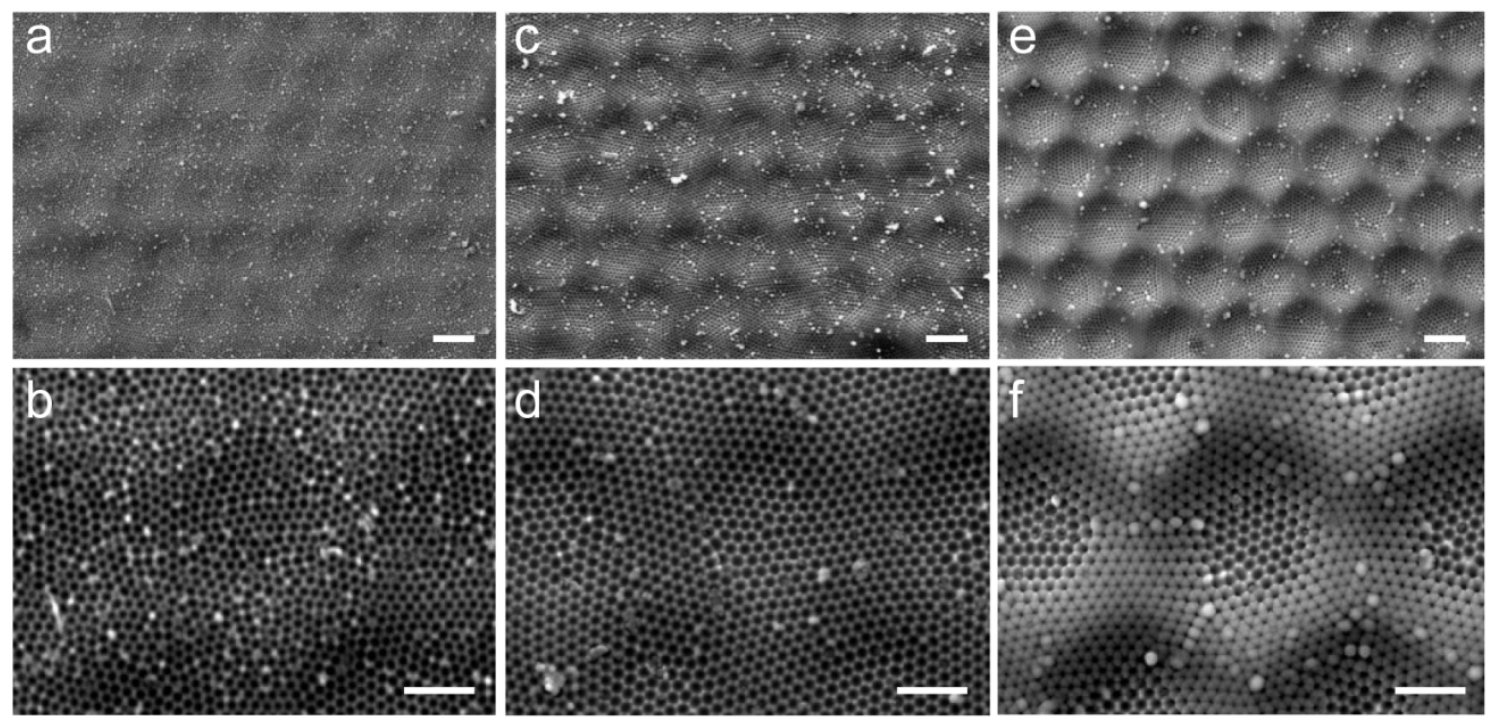

Figure S5. The SEM images of the ANA substrates taken following the deposition of the 250-nm $\mathrm{SiO}_{2}$ films and the PS-MS removal. The PS-MS diameters are: (a, b) $1.0 \mu \mathrm{m},(\mathrm{c}, \mathrm{d}) 1.3$ $\mu \mathrm{m}$ and (e, f) $1.45 \mu \mathrm{m}$. The scale bars in (a), (c) and (e) are $1 \mu \mathrm{m}$ and in (b), (d) and (f) are 500 nm. 


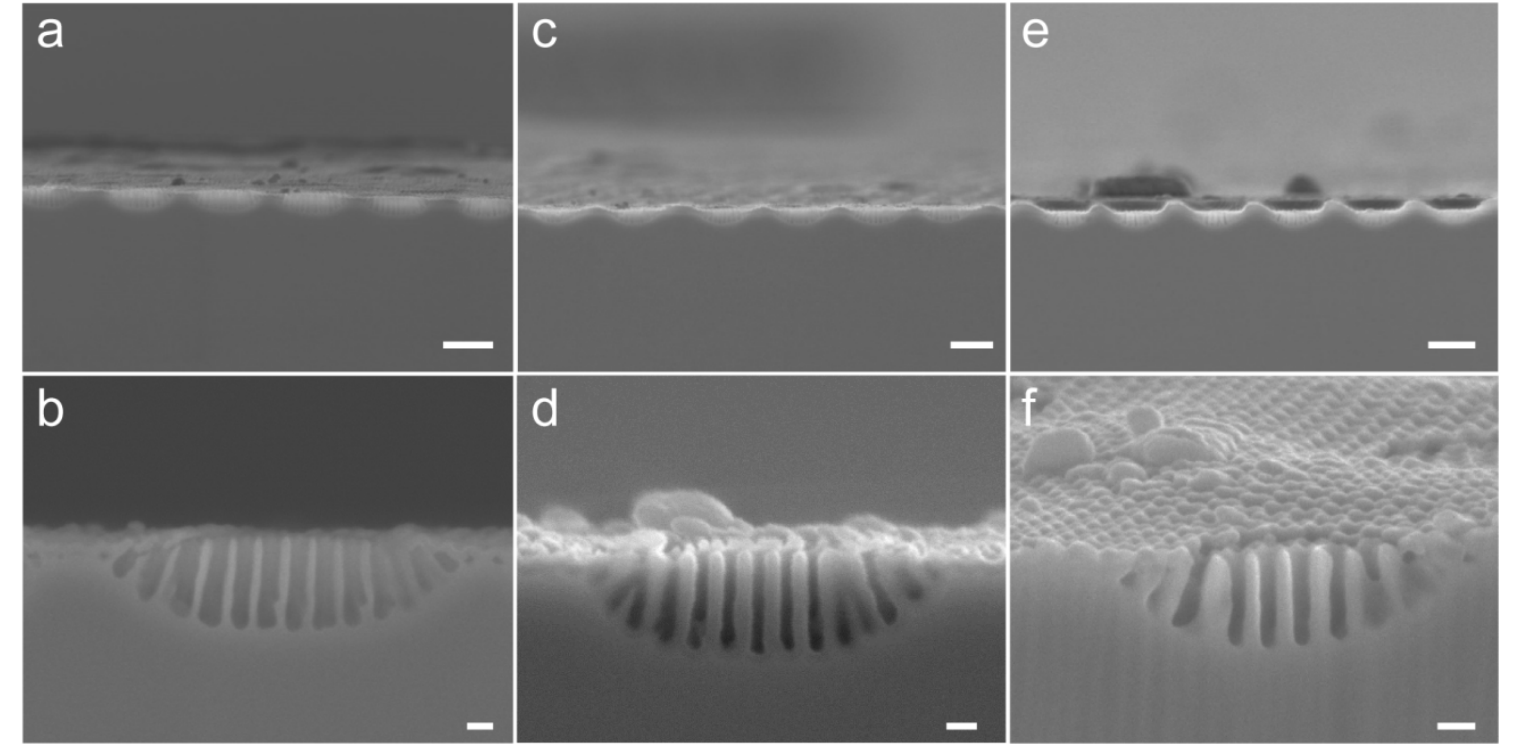

Figure S6. The cross-sectional SEM images for (a, b) hAAO-1.35, (c, d) hAAO-1.1, (e, f) hAAO-0.8. They are prepared by the second anodization for $10 \mathrm{~min}$. The scale bars in (a), (c) and (e) are $1 \mu \mathrm{m}$ and in (b), (d) and (f) are $100 \mathrm{~nm}$. 


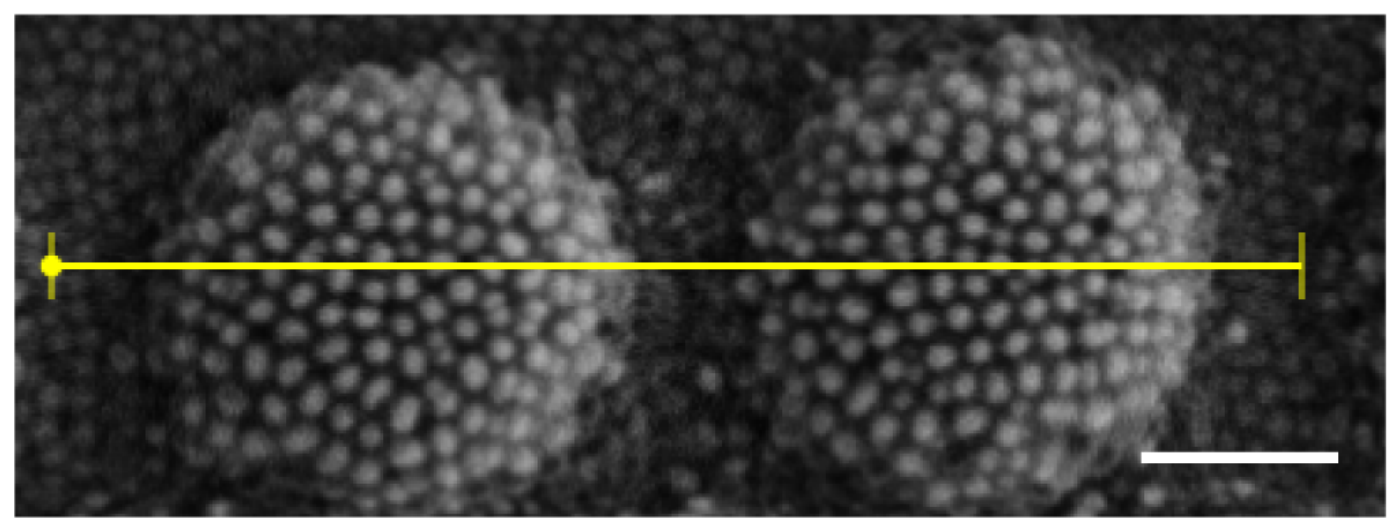

Ti $L a 1,2$

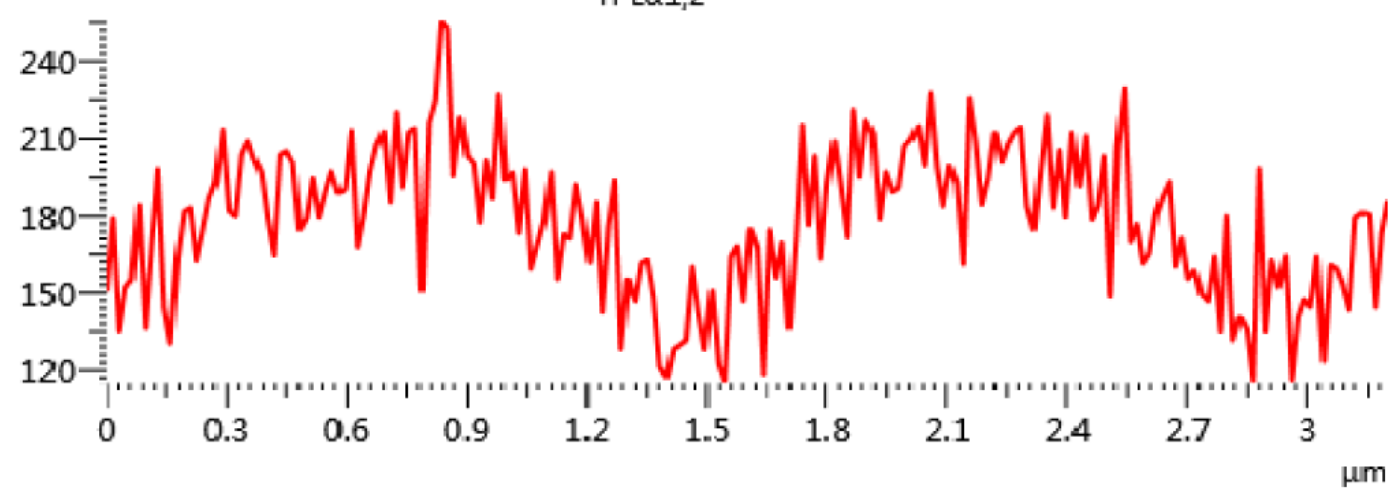

Figure S7. The SEM image and EDS line-scan for the Ti element of the radial $\mathrm{TiO}_{2}$ nanopillar array prepared by the ALD technique using the hAAO- 1.35 template. The scale bar is $1 \mu \mathrm{m}$. 

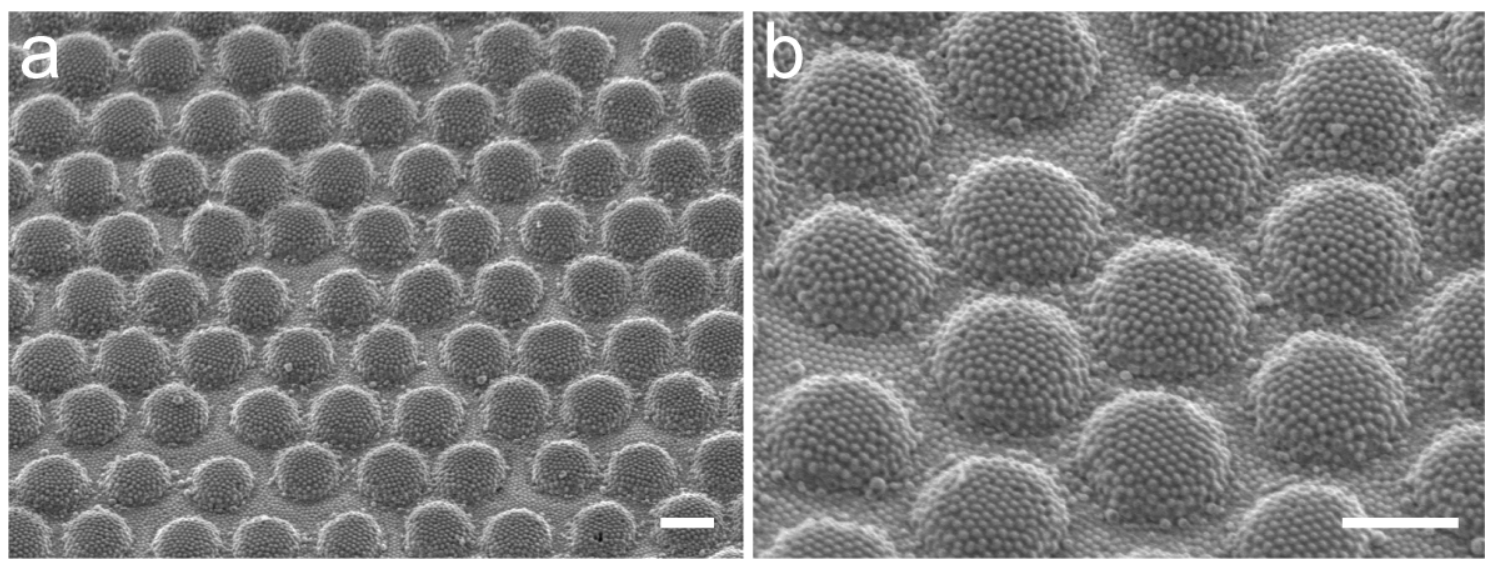

Figure S8. The SEM images of the radial $\mathrm{TiO}_{2}$ nanopillar array prepared using the hAAO-1.35 template taken at the titled angle of $20^{\circ}$. The scale bars are $1 \mu \mathrm{m}$. 

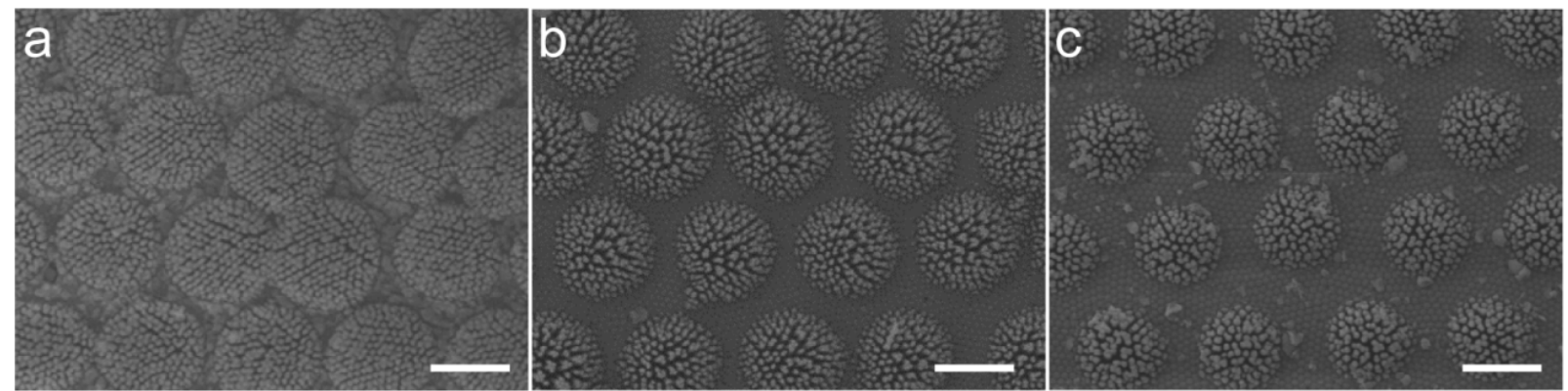

Figure S9. The SEM images of the radial $\mathrm{SiO}_{2}$ nanopillar arrays prepared using (a) hAAO-1.35,

(b) hAAO-1.1, (c) hAAO-0.8. The scale bars are $1 \mu \mathrm{m}$. 


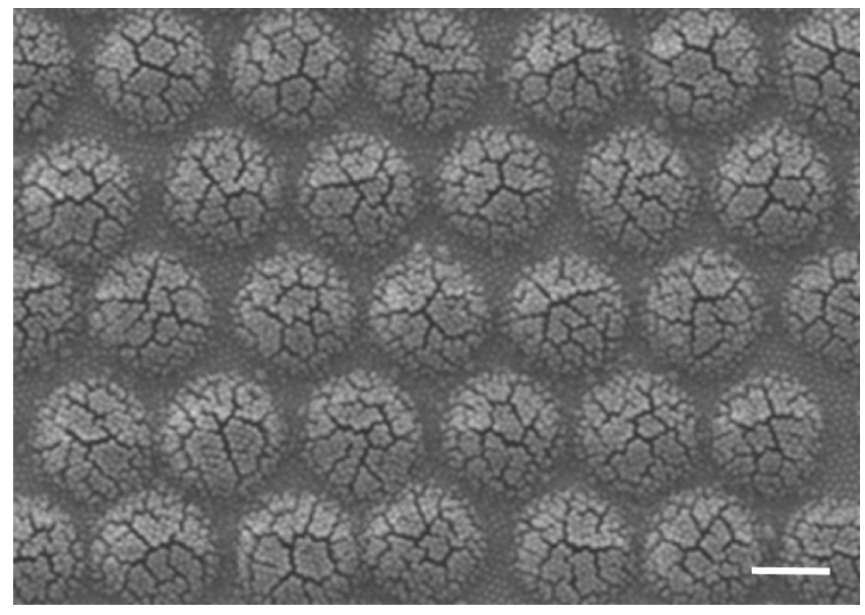

Figure S10. The SEM image of the radial PMMA nanopillar array prepared by the hAAO-1.35 template. The scale bar is $1 \mu \mathrm{m}$. 

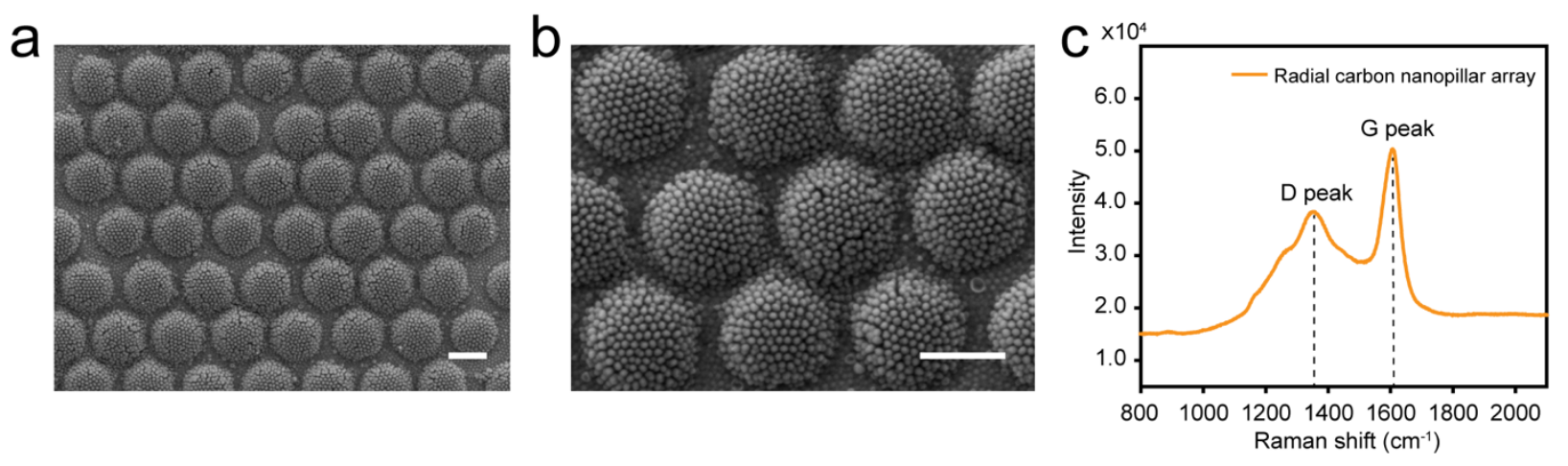

Figure S11. (a) The SEM image of the radial carbon nanopillar array prepared by the hAAO-1.35 template. (b) The zoomed-in SEM image of the unit cells. (c) The Raman spectrum of the radial carbon nanopillar array. The D peak and G peak, located at $1351 \mathrm{~cm}^{-1}$ and $1600 \mathrm{~cm}^{-1}$ are correspond to the signals of the disordered and graphitized carbon, respectively. The scale bars in (a) and (b) are $1 \mu \mathrm{m}$. 


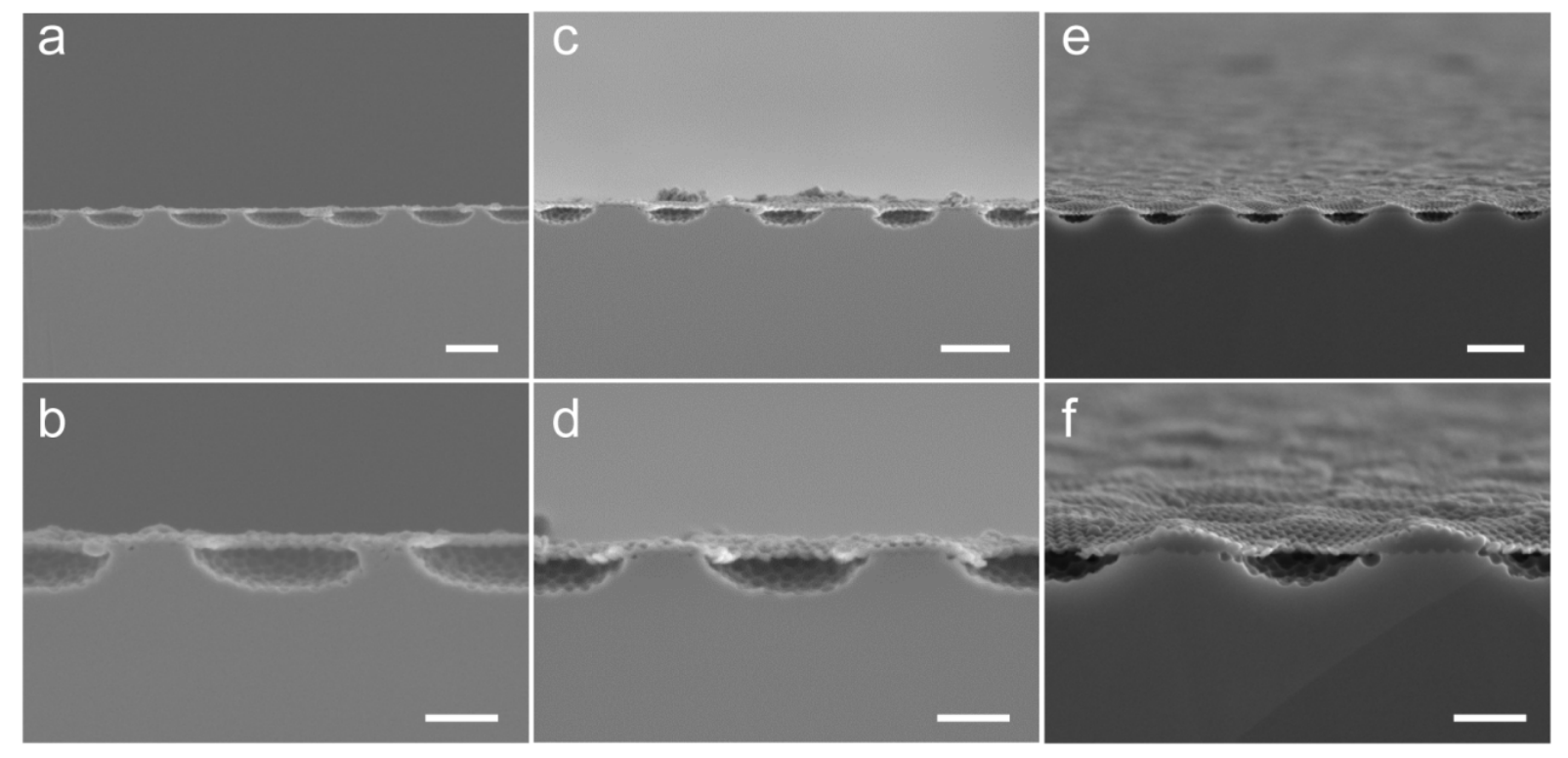

Figure S12. The cross-sectional SEM images of (a, b) D-hAAO-1.35, (c, d) D-hAAO-1.1, (e, f) D-hAAO-0.8. The scale bars in (a), (c) and (e) are $1 \mu \mathrm{m}$ and in (b), (d) and (f) are $500 \mathrm{~nm}$. 

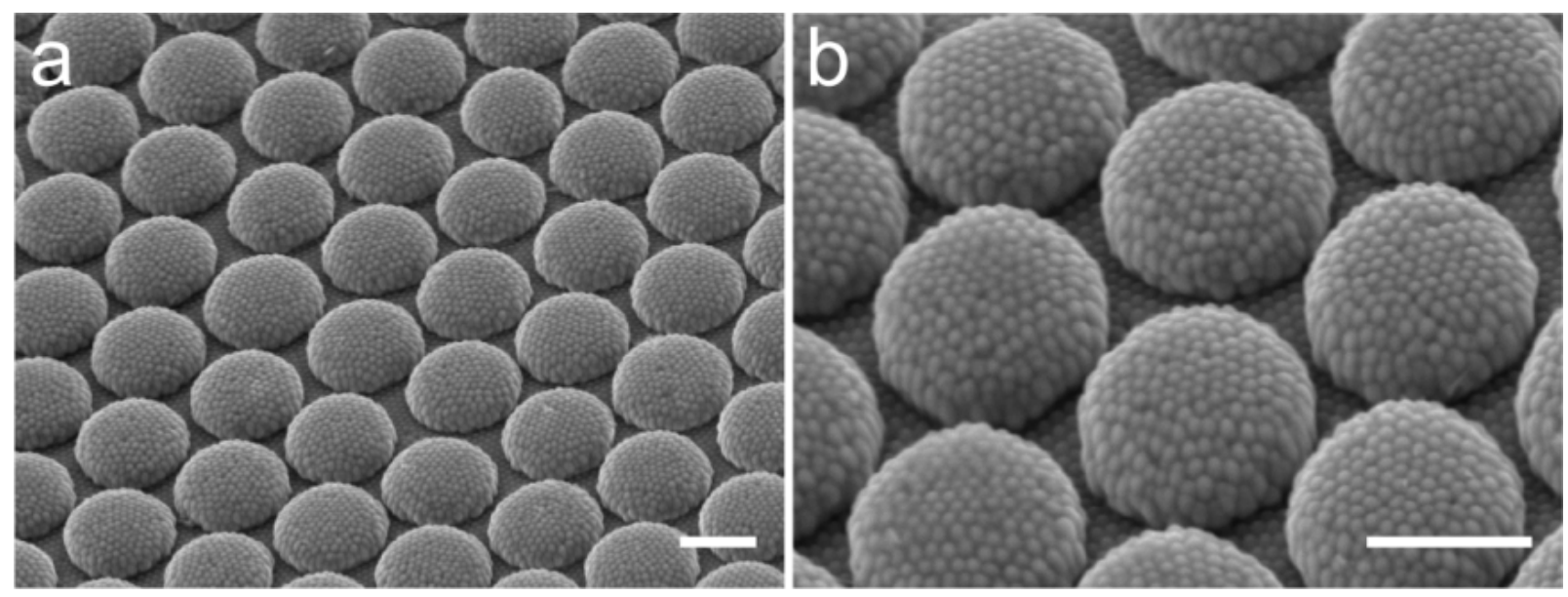

Figure S13. The SEM images of the moth-eye-like $\mathrm{TiO}_{2}$ nanoarray taken at the tilted angle of $45^{\circ}$. The scale bars are $1 \mu \mathrm{m}$. 


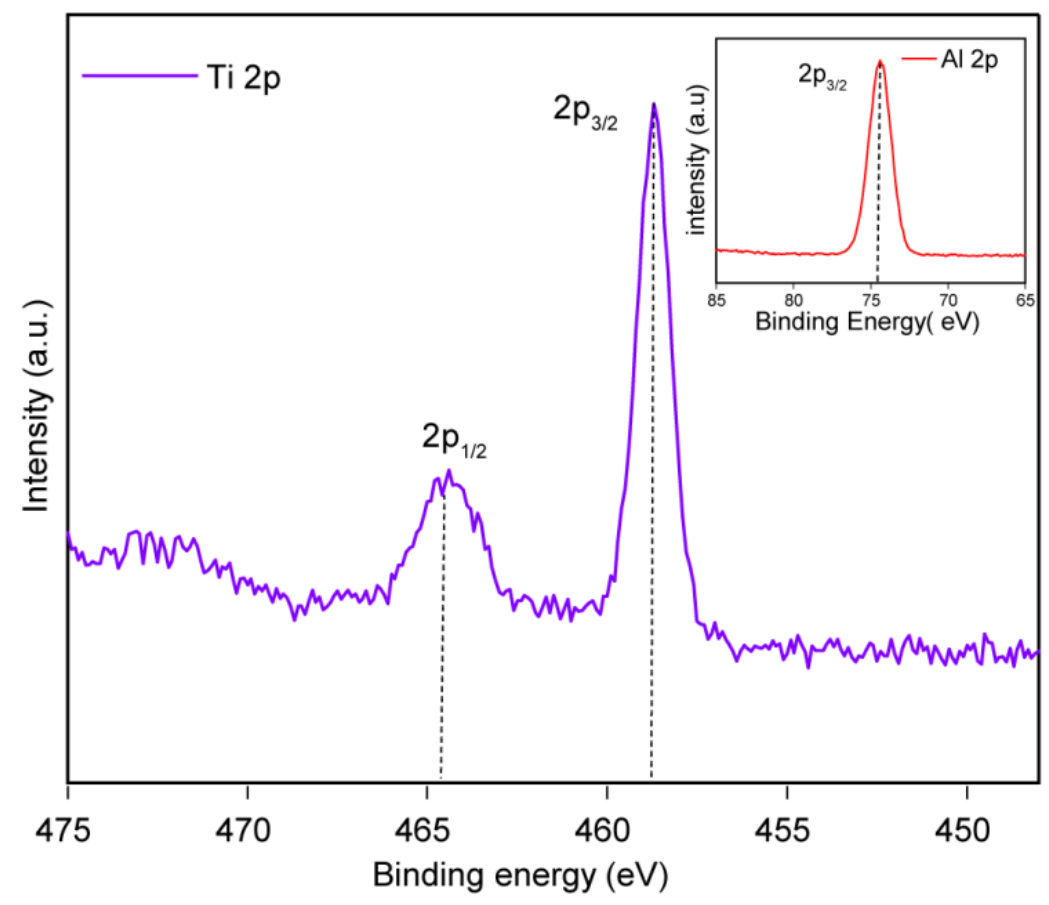

Figure S14. XPS spectra of the moth-eye-like $\mathrm{TiO}_{2}$ nanoarray prepared using the D-hAAO-1.35 template. The binding energies at $464.7 \mathrm{eV}$ and $458.9 \mathrm{eV}$ are corresponding to the $\mathrm{Ti} 2 \mathrm{p}_{1 / 2}$ and $2 \mathrm{p}_{3 / 2}$ orbits of $\mathrm{TiO}_{2}$. The inset shows the binding energy of $74.6 \mathrm{eV}$, which is corresponding to the $\mathrm{Al} 2 \mathrm{p}_{3 / 2}$ of $\mathrm{Al}_{2} \mathrm{O}_{3}$. 


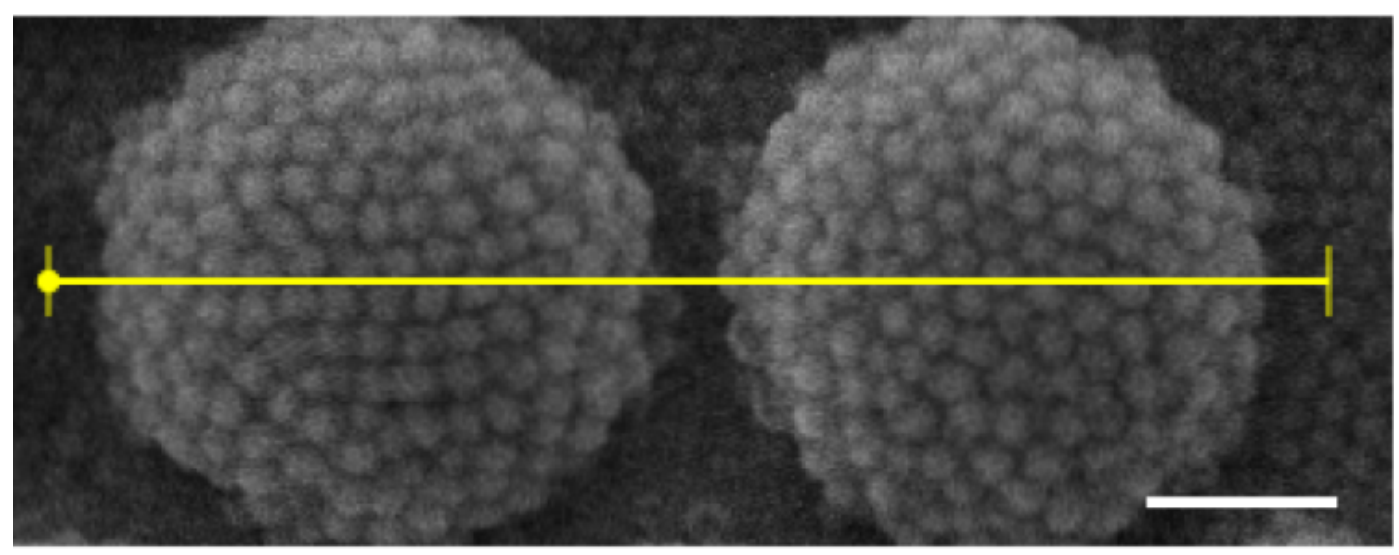

Ti La1,2

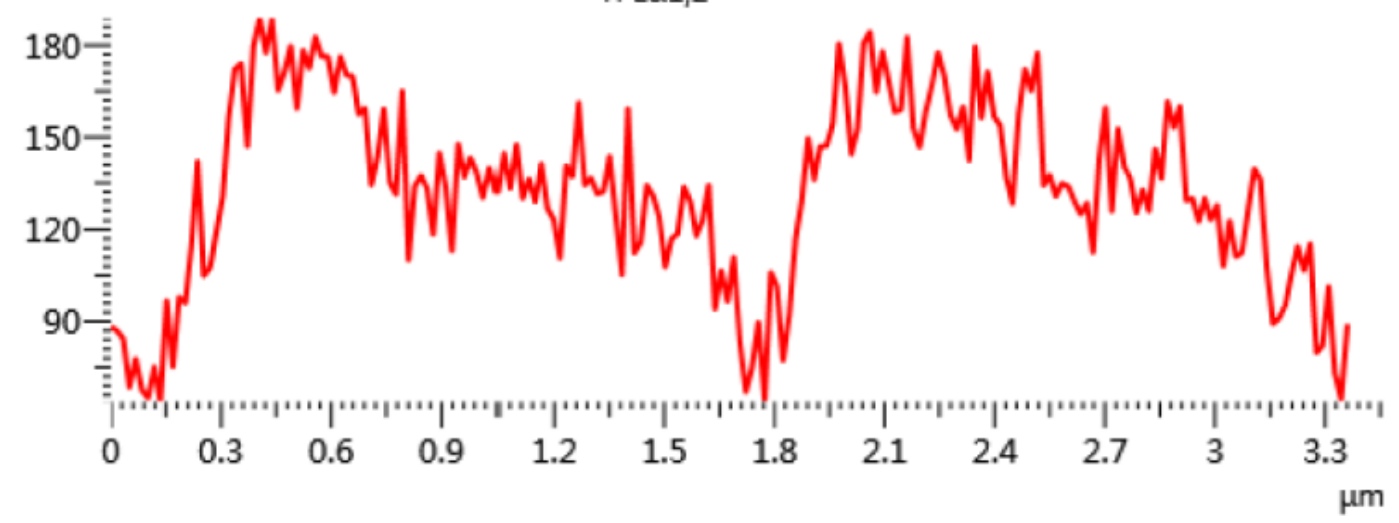

Figure S15. The SEM image and EDS line-scan for the Ti element of the moth-eye-like $\mathrm{TiO}_{2}$ nanoarray prepared by the D-hAAO-1.35 template. The scale bar is $1 \mu \mathrm{m}$. 

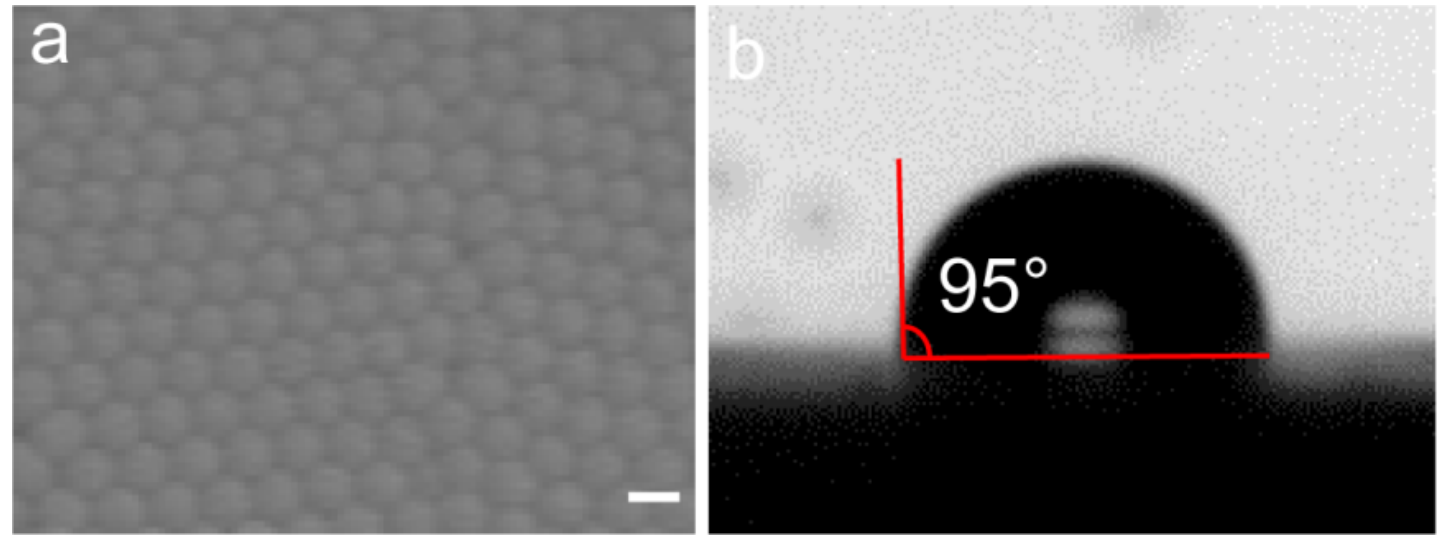

Figure S16. (a) The SEM image of the back side of the conventional AAO template. (b) The water contact angle for the substrate shown in (a). The scale bar is $100 \mathrm{~nm}$. 


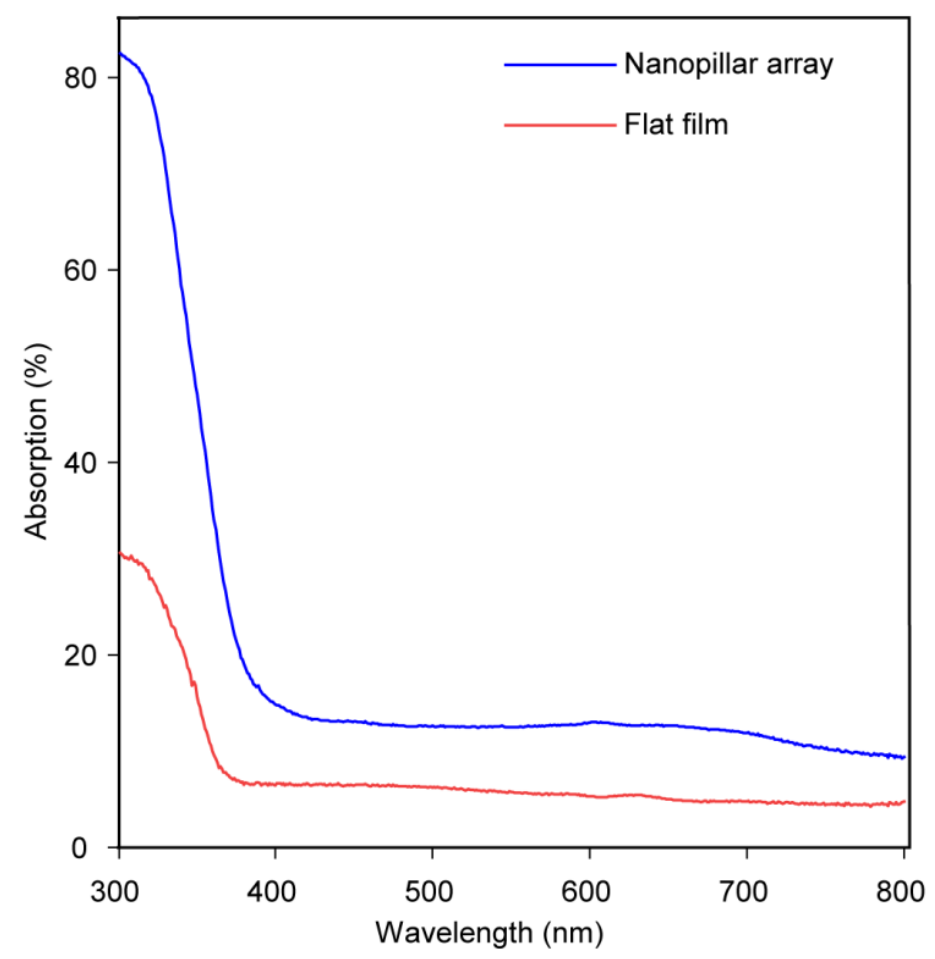

Figure S17. The UV-Vis absorption spectra of the radial $\mathrm{TiO}_{2}$ nanopillar array and the flat $\mathrm{TiO}_{2}$ film. 


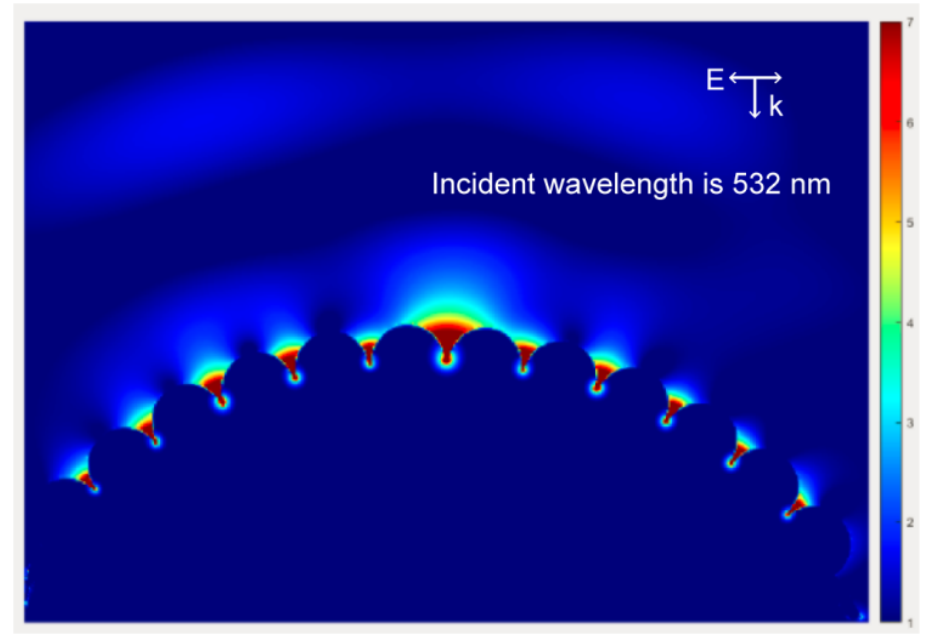

Figure S18. The finite difference time domain (FDTD) simulation for the moth-eye-like Ag nanoarray. The hot spots are concentrated at the regions between the Ag nano-hemispheres. The wavelength of the excited light is $532 \mathrm{~nm}$. 


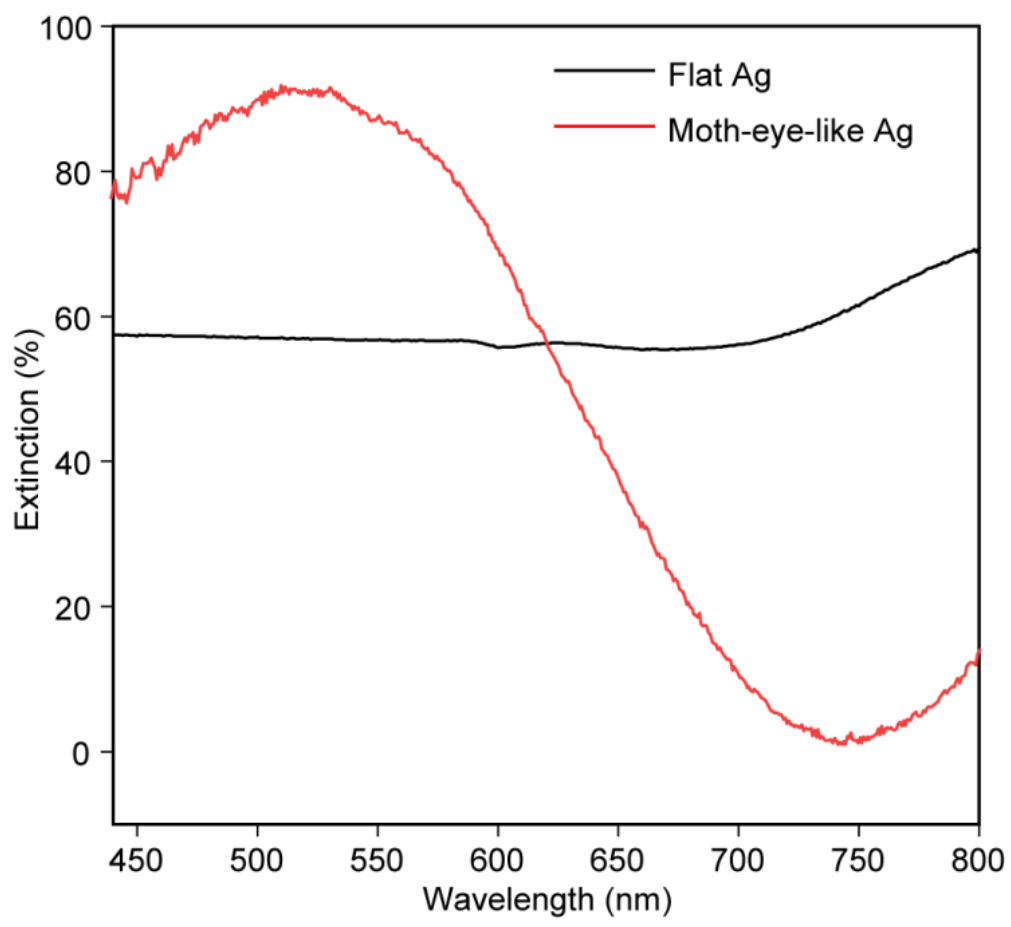

Figure S19. Extinction spectra of the moth-eye-like Ag nanoarray and the flat Ag film. The moth-eye-like Ag nanoarray has a plasma resonance peak at $530 \mathrm{~nm}$, while there is no plasma resonance peak for the flat $\mathrm{Ag}$ film. 


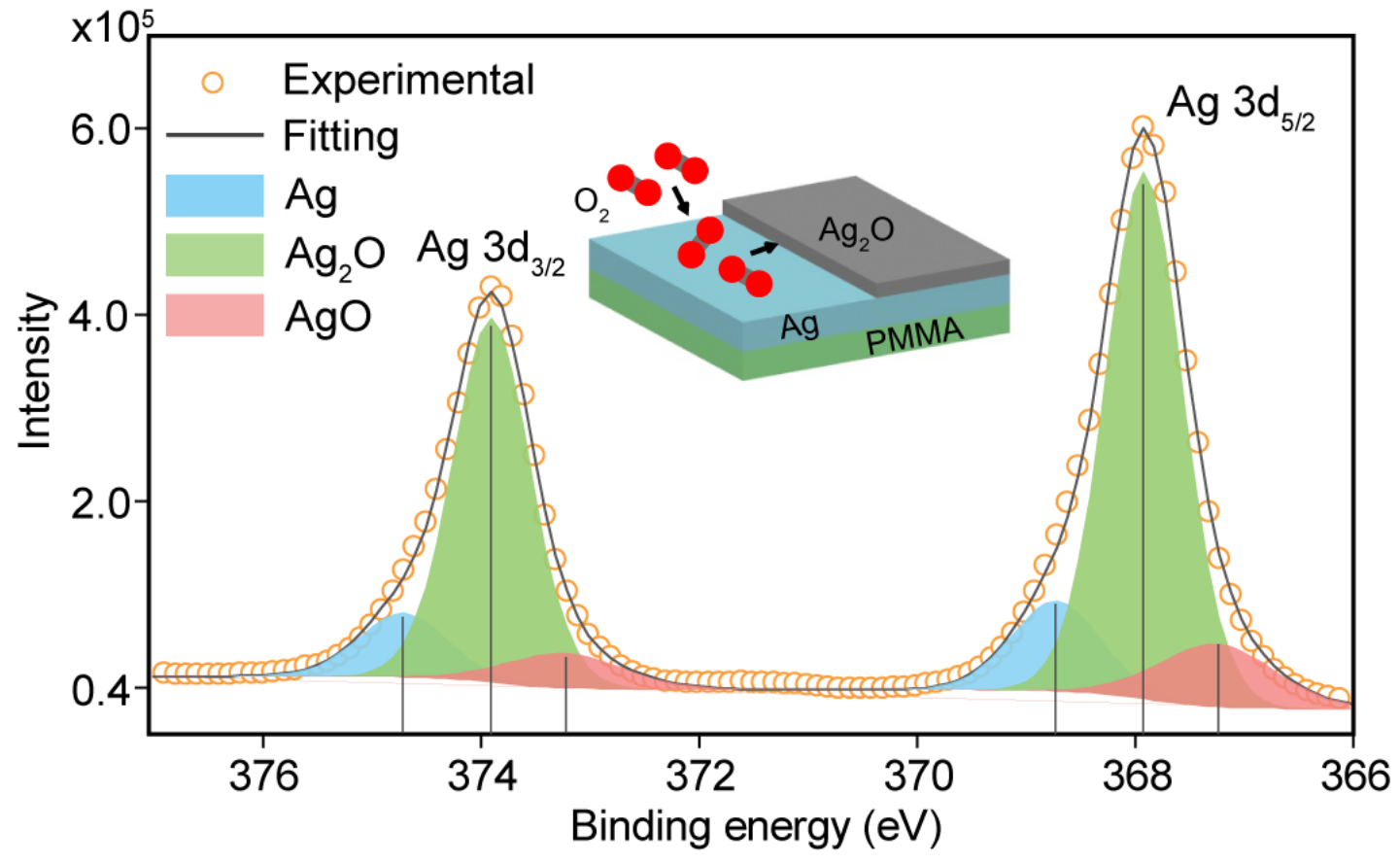

Figure S20. XPS spectrum of the flat Ag film taken after storing in air for two months. The relative humidity is $80 \%$. 


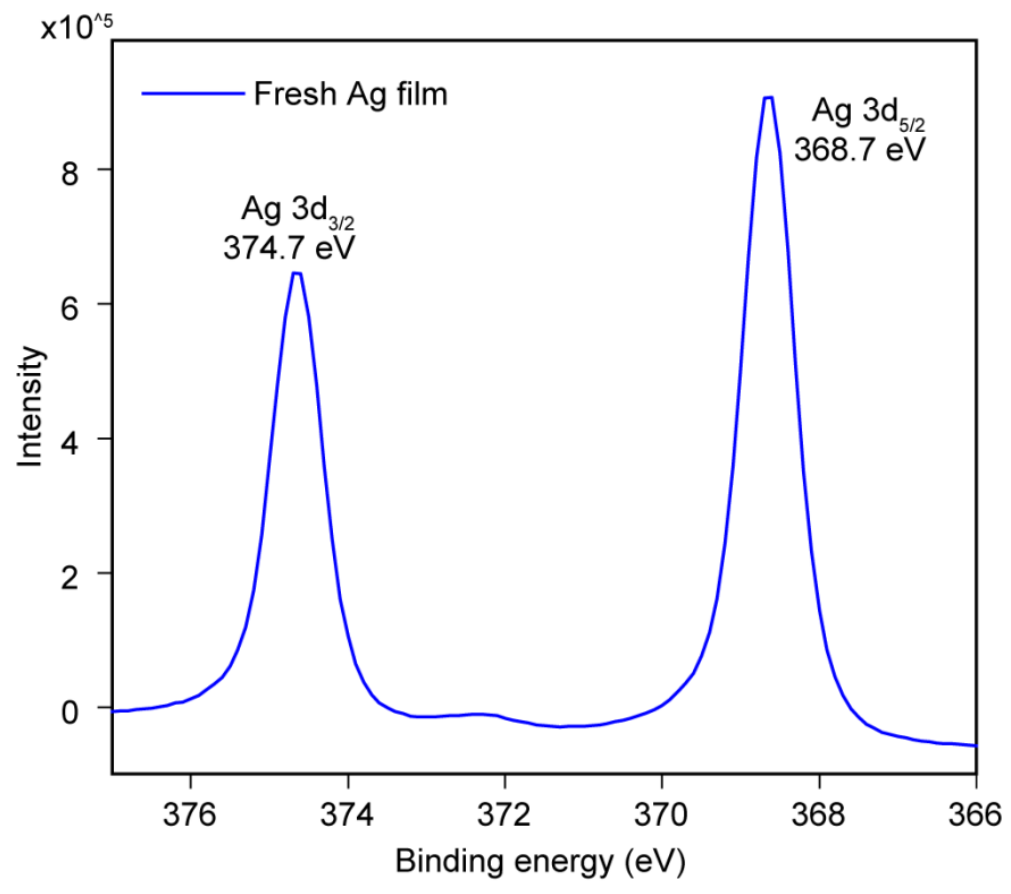

Figure S21. XPS spectrum of the fresh $\mathrm{Ag}$ film. The peak at $368.6 \mathrm{eV}$ is ascribed to $3 \mathrm{~d}_{5 / 2}$ orbit of the pure silver. 


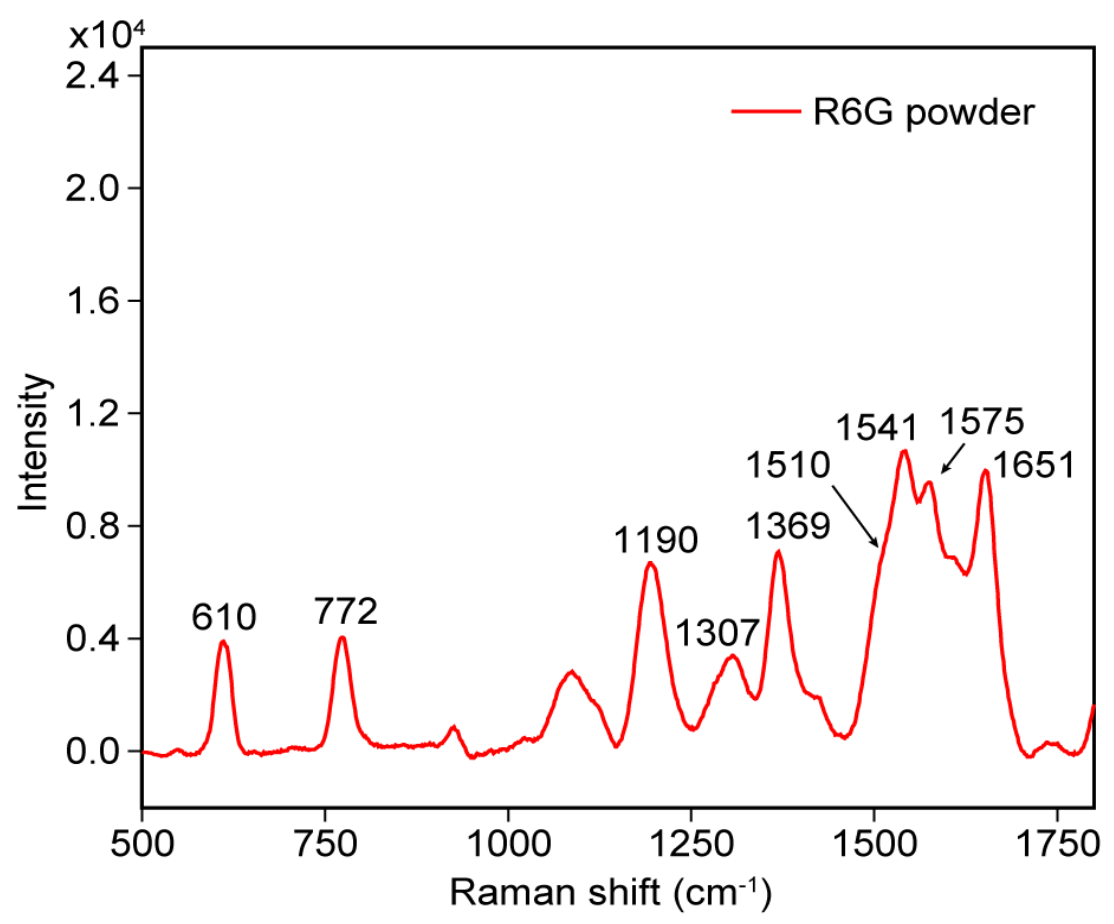

Figure S22. Raman spectrum of the R6G powder. The peaks located at $610 \mathrm{~cm}^{-1}$ is corresponding to the C-C-C in-plane vibration. The peaks located at 772 and $1190 \mathrm{~cm}^{-1}$ can be respectively attributed to the out-of-plane and in-plane vibrations of the $\mathrm{C}-\mathrm{H}$ bonds. The peaks located at $1307,1369,1510$ and $1651 \mathrm{~cm}^{-1}$ are assigned to the aromatic $\mathrm{C}-\mathrm{C}$ stretching vibration modes. The peak located at $1575 \mathrm{~cm}^{-1}$ is assigned to the $\mathrm{C}=\mathrm{O}$ stretching vibration mode. ${ }^{1,2}$

References:

1. Zhang, C.; Jiang, S.; Huo, Y.; Liu, A.; Xu, S.; Liu, X.; Sun, Z.; Xu, Y.; Li, Z.; Man, B. SERS detection of R6G based on a novel graphene oxide/silver nanoparticles/silicon pyramid arrays structure. Opt. Express 2015, 23, 24811-24821.

2. Wang, Y.; Ma, S.; Yang, Q.; Li, X. Size-dependent SERS detection of R6G by silver nanoparticles immersion-plated on silicon nanoporous pillar array. Appl. Surf. Sci. 2012, 258, 5881-5885. 

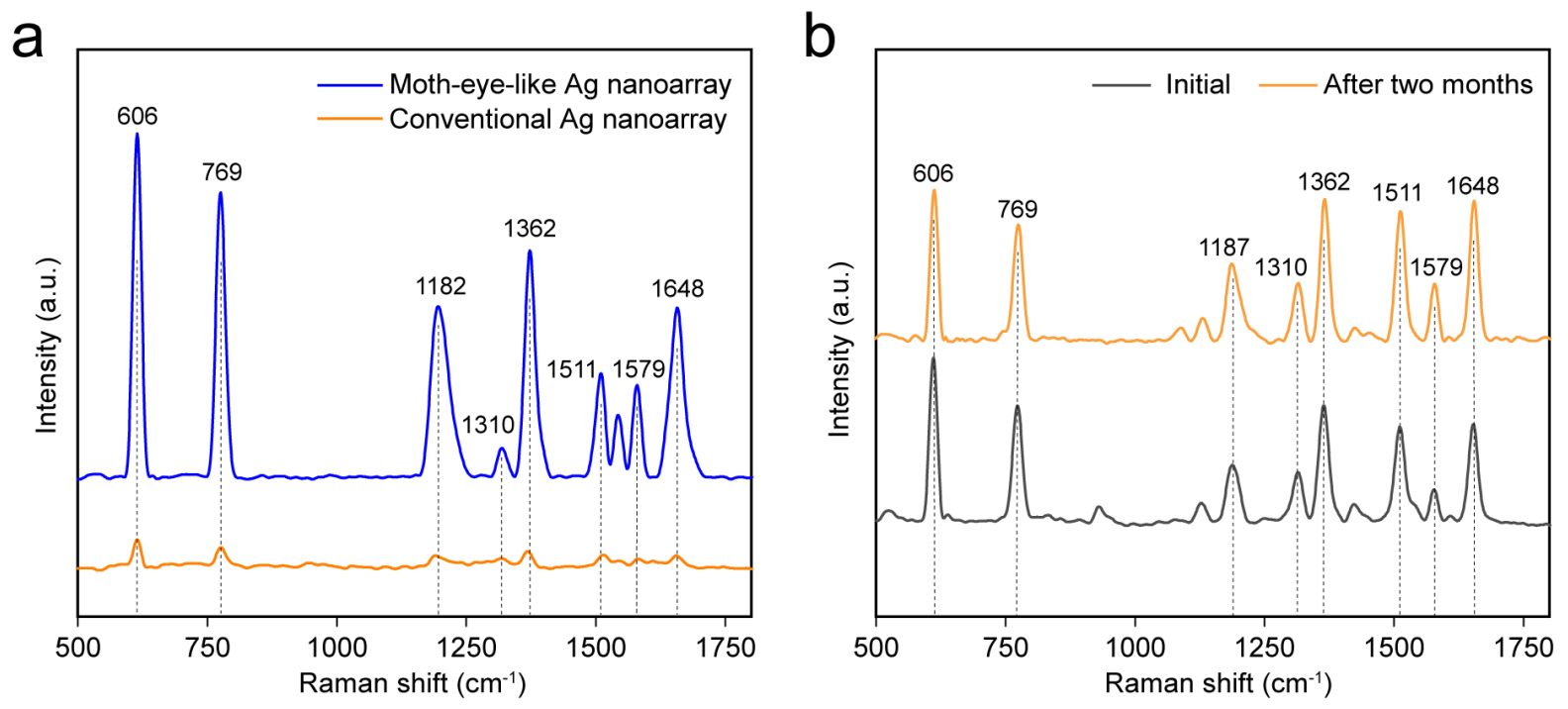

Figure S23. (a) The comparison of the SERS intensities for $10^{-7} \mathrm{M}$ R6G on the moth-eye-like Ag nanoarray and the $\mathrm{Ag}$ nanoarray fabricated by the conventional AAO template. (b) Raman spectra of $10^{-7} \mathrm{M}$ R6G taken on the Ag moth-eye-like nanoarray using the excitation wavelength of $532 \mathrm{~nm}$. The intensities of the characteristic peaks at $606,769,1182,1310,1362,1511$ and $1648 \mathrm{~cm}^{-1}$ are unvaried for the nanoarray stored in air for two months. 